\title{
Objective functions modification of GA optimized PID controller for brushed DC motor
}

\author{
A. A. M. Zahir, S. S. N. Alhady, W. A. F. W. Othman, A. A. A. Wahab, M. F. Ahmad \\ School of Electrical and Electronic Engineering, Universiti Sains Malaysia, Malaysia
}

\begin{tabular}{l}
\hline \hline Article Info \\
\hline Article history: \\
Received Jun 17, 2019 \\
Revised Oct 30, 2019 \\
Accepted Nov 24, 2019 \\
\hline
\end{tabular}

\section{Keywords:}

Error criteria

Genetic algorithm

Objective function

PID controller

PID tuning method

\begin{abstract}
PID Optimization by Genetic Algorithm or any intelligent optimization method is widely being used recently. The main issue is to select a suitable objective function based on error criteria. Original error criteria that is widely being used such as ITAE, ISE, ITSE and IAE is insufficient in enhancing some of the performance parameter. Parameter such as settling time, rise time, percentage of overshoot, and steady state error is included in the objective function. Weightage is added into these parameters based on users' performance requirement. Based on the results, modified error criteria show improvement in all performance parameter after being modified. All of the error criteria produce $0 \%$ overshoot, $29.51 \%-39.44 \%$ shorter rise time, $21.11 \%-42.98 \%$ better settling time, $10 \%$ to $53.76 \%$ reduction in steady state error. The performance of modified objective function in minimizing the error signal is reduced. It can be concluded that modification of objective function by adding performance parameter into consideration could improve the performance of rise time, settling time, overshoot percentage, and steady state error.
\end{abstract}

Copyright @ 2020 Institute of Advanced Engineering and Science. All rights reserved.

Corresponding Author:

Syed Sahal Nazli Alhady Syed Hassan,

School of Electrical and Electronic Engineering,

Universiti Sains Malaysia,

USM Engineering Campus, Seberang Perai Selatan, Nibong Tebal, Penang 14300, Malaysia.

Email: sahal@usm.my

\section{INTRODUCTION}

The main objective of this paper is to evaluate the performance of modified error criteria selected as objective function in optimizing the value of $\mathrm{K}_{\mathrm{P}}, \mathrm{K}_{\mathrm{I}}$, and $\mathrm{K}_{\mathrm{D}}$ for velocity control PID controller by using Genetic Algorithm for brushed DC motor. The effect of adding four PID performance parameters that is overshoot percentage, steady state error, settling time and rise time into objective function equation is analyzed by using Genetic Algorithm optimization. DC motor is widely being used in industry due to its low cost, facileness to control, good braking. and good speed regulation performance [1-4].

Genetic Algorithm is widely being used as an optimizer such as in project planning [5], exergoeconomic optimization for geothermal power plant [6], and PID optimization [7]. There is a lot of control method such as conventional PID controller, LQR controller [8], neural network controller [9], fuzzy controller [10-12]. Recently there is a lot of intelligent optimization method such as Genetic Algorithm (GA), Particle Swarm Optimization (PSO), Artificial Bee colony, Firefly Algorithm, and Bacterial Foraging (BF) [7, 13-23].

Authors in [15] optimized the PID controller by using PSO and compare the results with GA and Ziegler-Nichols. From the results PSO eliminates the overshoot, while GA and Ziegler-Nichols produced some overshoot. In terms of settling time, PSO is the best followed by GA and Ziegler-Nichols. The difference of settling time between GA and Ziegler-Nichols is not significant. It could be seen that Ziegler-Nichols have better rise time than GA and PSO [15]. The PSO could not surpass Ziegler-Nichols in 
terms of rise time due to the PSO optimization that only consider error function to optimize the PID. By adding rise time component into error criteria, the PID performance could have improve in rise time performance.

Authors in [17] used Genetic Algorithm to compare the performance of original error criteria, Mean of the Squared Error (MSE), Integral of Time multiplied by Absolute Error (ITAE), Integral of Absolute magnitude of the Error (IAE), Integral of the Squared Error (ISE), and Integral of Time multiplied by the Squared Error (ITSE) to tune PID controller to compensate the effect of time delay in the system. It is clear that by using GA that the percentage of overshoot is smaller compared with Ziegler-Nichols and iterative method but by using original error criteria the percentage of overshoot is still present. The settling time obtained by using original error criteria (GA) does not have significant difference compared with Ziegler-Nichols and Iterative Method. It could be seen that the rise time of Ziegler-Nichols is better than optimization by using GA-original error criteria [17]. Therefore, based on authors' work, the GA optimization could not perform better in terms of rise time and yield small improvement in settling time compare with Ziegler-Nichols method which is only a classical tuning method. The original error criteria that only focusing on minimizing the error without considering settling time and rise time component is the reason for slower rise time and insignificant improvement in settling time.

Based on works in [15] and [17] works that produce worse rise time and insignificant settling time improvement when optimizing PID by using GA compare with Ziegler-Nichols, therefore this paper intend to add settling time, rise time component into original error criteria formulas that only consider function of error when optimizing the gains value. Therefore, based on the related works above author intended to add overshoot percentage, steady state error, settling time, and rise time component into the error criteria such as ITAE, IAE, ISE, and ITSE to be optimized by using GA. GA optimization by using original objective functions only consider minimizing function of error, when iterating the optimal gains values. Besides integrating the error function only, performance parameter such as overshoot percentage, $\mathrm{O}_{v}$, steady state error, $\mathrm{SS}_{\mathrm{e}}$, rise time, $\mathrm{t}_{\mathrm{r}}$, and settling time, $\mathrm{t}_{\mathrm{s}}$, is added with the original objective functions to ensure that optimization process also include other performance indicators as criteria to produce optimum results. Based on the modification, the performance for all of error criteria shows improvement in eliminating the overshoot percentage to $0 \%$, reducing the rise time by $29.51 \%-39.44 \%$, decreasing the settling time by $21.11 \%-42.98 \%$, and reducing the steady state error by $10 \%-53.76 \%$. The details analysis is evaluated as in the results and discussion.

\section{RESEARCH METHOD}

\subsection{Brushed DC motor}

The system of brushed DC motor modeled PPSM63-L01 manufactured by Shanghai Dixi Technical Co. Ltd is identified. The bump test was conducted in order to determine the systems of the motor based on the velocity as the output and the voltage as the input. The final form of the transfer function that of the brushed dc motor is as in (1) follow:

$$
G(s)=\frac{104.9}{s^{2}+103.5 s+2617}
$$

\subsection{PID tuned by genetic algorithm}

Previously in [24], authors compared the Genetic Algorithm tuning of PID with Ziegler Nichols and Skogestad IMC. Author had previously compared the modified ITAE function with classical design formulas. In this paper author intended to evaluate in details the effect of modification on ITAE, ISE, IAE and ITSE error criterion. The objective function based on four different error criteria that is being used in GA optimization of PID controller can be described in (6-9) below.

$$
\begin{aligned}
& I T A E=\int_{0}^{\tau} t|e(t)| d t \\
& I A E=\int_{0}^{\tau}|e(t)| d t \\
& I S E=\int_{0}^{\tau} e(t)^{2} d t
\end{aligned}
$$




$$
\begin{aligned}
& \text { ITSE }=\int_{0}^{\tau} t e(t)^{2} d t \\
& I T A E_{\text {Modified }}=\int_{0}^{\tau} t|e(t)| d t+\alpha \mathrm{O}_{v}+\beta S S_{e}+\delta t_{s}+\gamma t_{r} \\
& I A E_{\text {Modified }}=\int_{0}^{\tau}|e(t)| d t+\alpha \mathrm{O}_{v}+\beta S S_{e}+\delta t_{s}+\gamma t_{r} \\
& I S E_{\text {Modified }}=\int_{0}^{\tau} e(t)^{2} d t+\alpha \mathrm{O}_{v}+\beta S S_{e}+\delta t_{s}+\gamma t_{r} \\
& I T S E_{\text {Modified }}=\int_{0}^{\tau} t e(t)^{2} d t+\alpha \mathrm{O}_{v}+\beta S S_{e}+\delta t_{s}+\gamma t_{r}
\end{aligned}
$$

where $\mathrm{e}(\mathrm{t})$ is error signal, $\mathrm{O}_{\mathrm{v}}$ is overshoot percentage, $\mathrm{SS}_{\mathrm{e}}$ is steady state error, $\mathrm{t}_{\mathrm{s}}$ is settling time, and $\mathrm{t}_{\mathrm{r}}$ is rise time. $\alpha, \beta, \delta$, and $\gamma$ indicate weightage for each performance parameter. Weightage is assigned for each parameter. User could defined the weightage based on their design requirement or priorities. Based on observation, by using weightage of $\alpha=1.5, \beta=15, \delta=7$, and $\gamma=1$, the plant as in (1) achieve desirable performance. The total value of right hand side of each equation in (2-9) is defined as objective function value.

After modifying as in (6-9), small value of the objective function could not be used as an indicator to evaluate the performance of the objective function as the objective function have additional work in considering the error signal is small simultaneously with considering others performance parameters. The modified objective function did not work solely on integrating the error signal, e(t) only but also considering the performance parameters. In this case the objective function value is evaluated by applying the fix value of PID gains into the objective function. $K_{P}, K_{I}$, and $K_{D}$ values used is $549.44,7.8925 \times 10^{3}$, and 4.0679 respectively. The gain values is obtained from ITSE modified objective function. Fix value is used so that the comparison of the output objective function value could be done fairly as the fixed variable is $\mathrm{K}_{\mathrm{P}}, \mathrm{K}_{\mathrm{I}}$, and $\mathrm{K}_{\mathrm{D}}$.

The main objective of the GA is to optimized the value of $K_{P}, K_{I}$, and $K_{D}$ based on the objective function assigned. The block diagram of PID tuned by GA is shown in Figure 1. The general process of genetic algorithm process is represented in Figure 2. The process of genetic algorithm to tune the PID gain can be described as follow:

- $K_{p}, K_{I}$, and $K_{D}$ is set as the unknown parameter to be optimized by GA. The initial population is set up to 50. The population type used is double vector as the problem involved mixed integer value. The lower bound and upper bound of the output is set as [0 000$]$ and [700 8000 5] respectively.

- The population is evaluated whether it fulfills the stopping criteria.

- If the stopping criteria is not fulfilled, the parent is selected based on the fitness of the chromosomes. The elite count created in this simulation is 0.1

- New children is created by using crossover and mutation. Crossover Fraction is set to 0.8. The mutation function used is based on the constrain condition. For constrained condition the algorithm randomly generate directions influenced by the previous generation. For unconstrained problem, the algorithm add random number to vector entry of an individual based on Gaussian distribution.

- Process 1 to 4 is repeated until stopping criteria is fulfilled. The stopping criteria is based on the average change of objective function values. If the average change of objective function values is less than objective function tolerance, 0.000001 for at least 50 latest generation, the GA is terminated. In a condition where the stopping criteria is not achieved, GA proceed until it reached maximum 300 generations.

- Simulation is repeated for 20 times to obtained the standard deviation of objective function value to observe the consistency of data. $K_{p}, K_{I}$, and $K_{D}$ that have the smallest value of objective function is selected to represent the error criteria. 


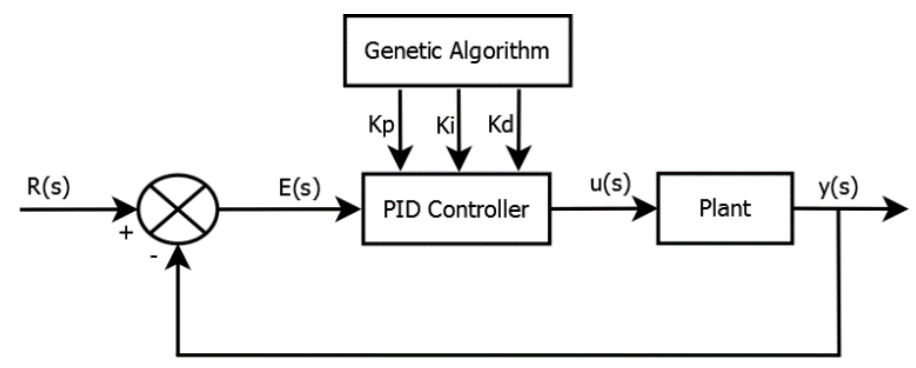

Figure 1. Block diagram of PID tuned by GA [24]

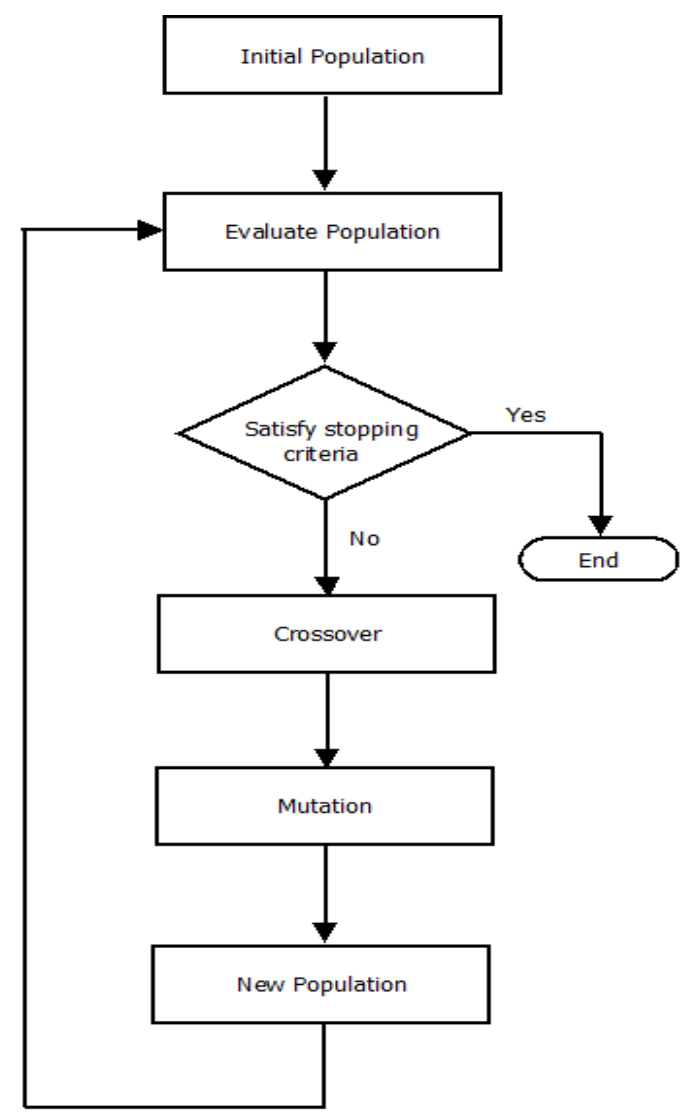

Figure 2. General process of genetic algorithm [24]

\section{RESULTS AND ANALYSIS}

Based on the results obtained from the simulation, it could be seen that the performance in terms of rise time, settling time, overshoot percentage and steady state error are improved significantly. The value of gains is tabulated in Tables 1 and 2. The modified objective function yields bigger value of proportional and derivative gain while the integral gain changes are not significant. The results show clearly that the objective function value increased after the objective function is modified. As stated in methodology, the original objective function aims is to minimize the error signal, but after being modified a small value did not indicates that the objective function have the best performances as there is additional component in the equation.

Table 1. $\mathrm{K}_{\mathrm{P}}, \mathrm{K}_{\mathrm{I}}$ and $\mathrm{K}_{\mathrm{D}}$ values of original objective functions optimized by $\mathrm{GA}$

\begin{tabular}{ccccc}
\hline \multirow{2}{*}{ Gain } & \multicolumn{4}{c}{ Original Objective Function } \\
& ITAE & IAE & ISE & ITSE \\
\hline $\mathrm{K}_{\mathrm{P}}$ & 314.13 & 317.42 & 389.66 & 353.49 \\
$\mathrm{~K}_{\mathrm{I}}$ & 7954.8 & 7972.1 & 7938.5 & 7999.8 \\
$\mathrm{~K}_{\mathrm{D}}$ & 2.7802 & 3.0011 & 2.9074 & 3.02 \\
\hline
\end{tabular}


Table 2. $\mathrm{K}_{\mathrm{P}}, \mathrm{K}_{\mathrm{I}}$ and $\mathrm{K}_{\mathrm{D}}$ values of modified objective functions optimized by GA

\begin{tabular}{ccccc}
\hline \multirow{2}{*}{ Gain } & \multicolumn{4}{c}{ Modified Objective Function } \\
& ITAE & IAE & ISE & ITSE \\
\hline $\mathrm{K}_{\mathrm{P}}$ & 549.4445 & 565.29 & 574.7 & 562.201 \\
$\mathrm{~K}_{\mathrm{I}}$ & 7892.5 & 7886 & 7703.6 & 7961.8 \\
$\mathrm{~K}_{\mathrm{D}}$ & 4.6079 & 4.7364 & 4.7968 & 4.7182 \\
\hline
\end{tabular}

Tables 3 and 4 shows the objective function value by using modified ITSE gain input. The gain values need to be fixed in order to make a fair comparison between the objective function. Based on the value of objective function in Tables 3 and 4, performance of GA could be evaluated. By using original objective functions, the cost/objective function value have smaller value than modified objective functions. This show that GA performed better by using original objective functions compare with modified objective functions in minimizing the error. However, in evaluating PID performance, four performance indicator that are rise time, settling time, steady state error, and overshoot percentage is more important because it influence the hardware performance. Based on the tabulation of the output performances in Tables 5, 6, 7, and 8, the response performance of modified objective functions improve significantly compared with original objective functions. The original objective function that focused solely on minimizing the error is the cause of the small value in the objective function. After being modified, others performance parameters is taken into consideration in iterating the value of gains indicates the reason of bigger value of objective function.

It can be concluded that ITSE have the best ability to minimize the error signal before and after being modified. The modification improve the ISE function and produce better value than ITAE function compared with before modification. Compare with previous work in [24] the original ITAE produce slower settling time with the presence of overshoot. The additional of overshoot and steady state error component into ITAE objective function eliminates overshoot percentage and reduce settling time, however modified ITAE function still produced slower rise time compared with original ITAE. The addition of rise time and settling time component as in (6-9) yields faster rise time compare with previous work in [25]. As in subtopics 3.41 , for ITAE the rise time performance improve by $39.44 \%$. The improvement in this parameter also could be seen in other modified error criteria.

Based on Table 1 and Table 2, the different value of $K_{P}, K_{I}$, and $K_{D}$ produced before and after the modification of objective functions yields different output step response. Proportional gain, $K_{P}$ is basically directly proportional to error function. Integral gain, $\mathrm{K}_{\mathrm{I}}$ is associated with reducing the steady state error. The derivatives terms work based on the rate of change of error signal of the systems [25]. $\mathrm{K}_{\mathrm{P}}$ for ITAE, IAE, ISE, and ITSE increase by $74.9 \%, 78.09 \%$, 47.49\%, and 59.04\% respectively. The increment in proportional gains caused the system that is optimized by using modified objective functions improve the response time of the system to reach the set point value. $K_{D}$ increment reduce the rise time of the systems. $\mathrm{K}_{\mathrm{I}}$ for ITAE, IAE, ISE, and ITSE before and after modification shows slightly decrement in values. The difference is by $0.79 \%, 1.08 \%, 2.96 \%$, and $0.48 \%$ for ITAE, IAE, ISE, and ITSE respectively.

Therefore the changes of $\mathrm{K}_{\mathrm{I}}$ values before and after the modification could not justify the decrement in steady state error as shown in Tables $5,6,7,8$ as the changes in $K_{I}$ values are insignificant. Thus it could be concluded that the major increment of $K_{P}$ is the main reason for the decrement in steady state error as gain component is proportional to error function. $\mathrm{K}_{\mathrm{D}}$ values for ITAE, IAE, ISE, and ITSE shows huge increment by $65.73 \%, 57.82 \%, 64.99 \%$, and $56.23 \%$ after all of the error criteria were being modified. The significant increment of $\mathrm{KD}$ values justified the reduction of overshoot percentage and reduction in settling time after the objective functions are modified.The details analysis for each error criteria performance based on the predefined performance indicators is discussed in subsection 3.1, 3.2, 3.3, and 3.4 below.

Table 3. Objective function values of original objective functions optimized by GA

\begin{tabular}{lcccc}
\hline & \multicolumn{4}{c}{ Original Objective Function } \\
& ITAE & IAE & ISE & ITSE \\
\hline Objective Function Value & $1.0163 \times 10^{-4}$ & 0.0112 & 0.010 & $5.8442 \times 10^{-7}$ \\
\hline
\end{tabular}

Table 4. Objective function values of modified objective functions optimized by GA

\begin{tabular}{ccccc}
\hline & \multicolumn{4}{c}{ Modified Objective Function } \\
& ITAE & IAE & ISE & ITSE \\
\hline Objective Function Value & 6.7020 & 6.7131 & 0.0764 & 0.0664 \\
\hline
\end{tabular}


Table 5. Performance of original and modified ITAE

\begin{tabular}{cccc}
\hline Performance Parameter & Original ITAE & Modified ITAE & Improvement \\
\hline Rise Time (s) & 0.0071 & 0.0043 & $39.44 \%$ \\
Settling Time (s) & 0.0115 & 0.0071 & $38.26 \%$ \\
Overshoot (\%) & 0.4822 & 0 & $100 \%$ \\
Steady State Error & 0.0047 & 0.0041 & $12.77 \%$ \\
Standard Deviation of Objective Function Values & $4.99 \times 10^{-6}$ & 1.707 & - \\
\hline
\end{tabular}

Table 6. Performance of original and modified IAE

\begin{tabular}{cccc}
\hline Performance Parameter & Original IAE & Modified IAE & Improvement \\
\hline Rise Time (s) & 0.0069 & 0.0042 & $39.13 \%$ \\
Settling Time (s) & 0.0121 & 0.0069 & $42.98 \%$ \\
Overshoot (\%) & 0 & 0 & $0 \%$ \\
Steady State Error & 0.0043 & 0.0022 & $48.84 \%$ \\
Standard Deviation of Objective Function Values & $1.218 \times 10^{-4}$ & 2.623 & - \\
\hline
\end{tabular}

Table 7. Performance of original and modified ISE

\begin{tabular}{cccc}
\hline Performance Parameter & Original ISE & Modified ISE & Improvement \\
\hline Rise Time (s) & 0.0061 & 0.0043 & $29.51 \%$ \\
Settling Time (s) & 0.009 & 0.0071 & $21.11 \%$ \\
Overshoot (\%) & 1.6644 & 0 & $100 \%$ \\
Steady State Error & 0.0093 & 0.0043 & $53.76 \%$ \\
Standard Deviation of Objective Function Values & $9.34 \times 10^{-6}$ & 0.0243 & - \\
\hline
\end{tabular}

Table 8. Performance of original and modified ITSE

\begin{tabular}{cccc}
\hline Performance Parameter & Original ITSE & Modified ITSE & Improvement \\
\hline Rise Time (s) & 0.0064 & 0.0042 & $34.38 \%$ \\
Settling Time (s) & 0.0103 & 0.0069 & $33.00 \%$ \\
Overshoot (\%) & 0.3827 & 0 & $100 \%$ \\
Steady State Error & 0.002 & 0.0018 & $10 \%$ \\
Standard Deviation of Objective Function Values & $6.48 \times 10^{-8}$ & 0.024 & \\
\hline
\end{tabular}

\subsection{Effect of modification on ITAE}

Based on Table 5, modified ITAE have $39.44 \%$ and $38.26 \%$ better rise time and settling time respectively. Based on Tables 1 and 2, the increment of KP value from 314.13 to 594.4445 is the reason behind the reduction The percentage of overshoot is reduced to 0 . The steady state error reduce by $12.77 \%$. By modifying the ITAE function, the performance improves the most in terms of settling time. The standard deviation value of original ITAE is $4.99 \mathrm{e}-06$, significantly smaller than modified ITAE, 1.707 indicates the inconsistency of data obtained from modified ITAE compared with original ITAE.

\subsection{Effect of modification on IAE}

In Table 6, modified IAE shows improvement of $39.13 \%$ and $42.98 \%$ for rise time and settling time respectively. The overshoot percentage is at the best before it modified, therefore the modification does not have any effect on this sector. The steady state error is reduced by $48.84 \%$. The effect of modification have the most impact on settling time performance.

\subsection{Effect of modification on ISE}

Original ISE yields the biggest overshoot percentage among all performance indices, $1.6644 \%$, after being modified the overshoot percentage become zero, this is due to the overshoot component is been taken into consideration when GA iterates the value of gains. The rise time reduced by $29.51 \%$ while settling time have reduced by $21.11 \%$. The steady state error have reduction by $53.76 \%$. The modification of ISE function improved overshoot component the most compared with other performance parameters. As in Table 7, the standard deviation become bigger due to the effect of modification effect the decision of GA to meet the stopping criteria because of the consideration for others performance parameter instead of the integral of error signal only.

\subsection{Effect of modification on ITSE}

Based on the comparison in paragraph 5 in results and discussion section, it can be seen that the performance of ITSE is the best at minimizing the error signal. The standard deviation of ITSE data is 
also the best compared with ITAE, IAE and ISE function. Based on Table 8, in terms of rise time and settling time, ITSE improved by $34.38 \%$ and $33.00 \%$ respectively after being modified. The overshoot percentage reduce from $0.3827 \%$ to $0 \%$. The steady state error produced is reduced by $10 \%$. It can be concluded that ITSE function have the biggest improvement in terms of rise time after being modified.

\section{CONCLUSION}

The effect of modification on error criteria as objective function in tuning the PID controller by using GA is evaluated. Performance parameter such as overshoot percentage, steady state error, rise time, and settling time is added into error criteria. The modification of the objective function seems to eliminate the overshoot percentage, reduce steady state error, settling time and rise time. The objective function value is increased after the objective function is being modified as the objective function considered the performance parameter to be optimized despite of minimizing the error signal only as in original objective function. In conclusion, overall performance of the systems could be improved by modifying the objective function as in (6-9).

\section{ACKNOWLEDGEMENTS}

This work was supported by Ministry of Science, Technology and Innovation (MOSTI) Malaysia, under the Science Fund grant scheme; grant number USM/305/PELECT/6013112 and USM/304/PELECT/6316200.

\section{REFERENCES}

[1] W. Yan, et al., "The PWM speed regulation of DC motor based on intelligent control," Systems Engineering Procedia, vol. 3, pp. 259-267. 2012.

[2] V. Sankardoss and P. Geethanjali, "Parameter estimation and speed control of a PMDC motor used in wheelchair," Energy Procedia, vol. 117, pp. 345-352, 2017.

[3] M. B. N. Shah, et al., "PID-based temperature control device for electric kettle," International Journal of Electrical and Computer Engineering, vol. 9, no. 3, pp. 1683, 2019.

[4] M.A. Shamseldin, et al. "A novel self-tuning fractional order PID control based on optimal model reference adaptive system," International Journal of Power Electronics and Drive System (IJPEDS), vol. 10, no. 1, pp. 230-241, 2019.

[5] Y. J. Chen, et al., "Using BIM model and genetic algorithms to optimize the crew assignment for construction project planning," International Journal of Technology, vol. 3, pp. 179-187, 2011.

[6] Nasruddin, et al., "Exergy analysis and exergoeconomic optimization of a binary cycle system using a multi objective genetic algorithm," International Journal of Technology, vol. 9, no. 2, pp. 275-286, 2018.

[7] T. O. Mahony, et al., "Genetic Algorithm for PID Parameter Optimization: Minimizing Error Criteria," Process Control and Instrumentation, pp. 148-153, 2000.

[8] P.S Devi and R.V. Santhi, "Introducing LQR-fuzzy for a dynamic multi area LFC-DR model," International Journal of Electrical and Computer Engineering (IJECE), vol. 9, no. 2, pp. 861-874, 2019.

[9] E. Buzi and P. Marango., "A Comparison of conventional and nonconventional methods of DC motor speed control," IFAC Proceedings, vol. 46, no. 8, pp. 50-53, 2013.

[10] A. Prayitno, et al., "Fuzzy Gain Scheduling PID Control for Position of the AR. Drone," International Journal of Electrical and Computer Engineering (IJECE), vol. 8, no. 4, pp. 1939-1946, 2018.

[11] C. F. Hsu and B. K. Lee, "FPGA-based adaptive PID control of a DC motor driver via sliding-mode approach," Expert Systems with Applications, vol. 38, no. 9, pp. 11866-11872, 2011.

[12] N. N. Baharudin, and S. M. Ayob., "Brushless DC Motor Speed Control Using Single Input Fuzzy PI Controller," International Journal of Power Electronics and Drive Systems (IJPEDS), vol. 9, no. 4, pp. 1952-1966, 2018.

[13] H. E. Ibrahim, et al., "Optimal PID control of a brushless DC motor using PSO and BF techniques," Ain Shams Engineering Journal, vol. 5, no. 2, pp. 391-398, 2014.

[14] A. A. Aly, "PID parameters optimization using genetic algorithm technique for electrohydraulic servo control system," Intelligent Control and Automation, vol. 2. no. 2, pp. 69, 2011.

[15] A. Sungthong, and W. Assawinchaichote, "Particle swam optimization based optimal PID parameters for air heater temperature control system," Procedia Computer Science, vol. 86, pp. 108-111, 2016.

[16] T. Samakwong and W. Assawinchaichote, "PID controller design for electro-hydraulic servo valve system with genetic algorithm," Procedia Computer Science, vol. 86, pp. 91-94, 2016.

[17] A. Mirzal, et al., "PID parameters optimization by using genetic algorithm," arXiv preprint arXiv:1204.0885, 2012.

[18] Y. A. Jaen-Cuellar, et al., "PID-controller tuning optimization with genetic algorithms in servo systems," International Journal of Advanced Robotic Systems, vol. 10, no. 9, pp. 324, 2013.

[19] M. A. Sahib and B. S. Ahmed., "A new multiobjective performance criterion used in PID tuning optimization algorithms," Journal of advanced research, vol. 7, no. 1, pp. 125-134, 2016. 
[20] G. A. Salman, et al., "Application of artificial intelligence techniques for LFC and AVR systems using PID controller," International Journal of Power Electronics and Drive Systems (IJPEDS), vol. 10, no. 3, pp. 1694-1704, 2019.

[21] M. A. Ibrahim, et al., "Optimal PID controller of a brushless DC motor using genetic algorithm," International Journal of Power Electronics and Drive Systems (IJPEDS), vol. 10, no. 2, pp. 822-830, 2019.

[22] M. M. A. Alqadasi, et al., "Optimization of PID for industrial electro-hydraulic actuator using PSOGSA," TELKOMNIKA (Telecommunication, Computing, Electronics and Control), vol. 17, no. 5, pp. 2625-2635, 2019.

[23] X. Huang, et al., "An enhanced hybridized artificial bee colony algorithm for optimization problems," International Journal of Artificial Intelligence, vol. 8, no. 1, pp. 87-94, 2019.

[24] A. A. M. Zahir, et al., "Genetic Algorithm Optimization of PID Controller for Brushed DC Motor," Intelligent Manufacturing \& Mechatronics: Proceedings of Symposium, 29 January 2018, Pekan, Pahang, Malaysia. Springer Singapore, pp. 427-437, 2018.

[25] J. W. Polderman and J. C. Willems, "Introduction to the mathematical theory of systems and control," New York, pp. 434, 1998.

\section{BIOGRAPHIES OF AUTHORS}

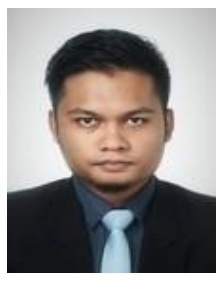

Ahmad Afiq Muhammad Zahir is currently pursuing his masters degree in electrical and electronic Engineering (Industrial Automation and Control) at Universiti Sains Malaysia. He obtained bachelor degree of engineering in Aerospace Engineering at Universiti Sains Malaysia. His current research interest are in control systems and artificial intelligence optimization.

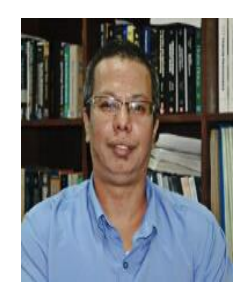

Syed Sahal Nazli Alhady Syed Hassan is currently a senior lecturer at School of Electrical and Electronic Engineering Universiti Sains Malaysia. His obtained his Bachelor of Engineering at Universiti Teknologi Mara and completed his M.Sc. and Ph.D at Universiti Sains Malaysia. His specializations are in neural networks, biomedical, embedded systems, and intelligent systems.

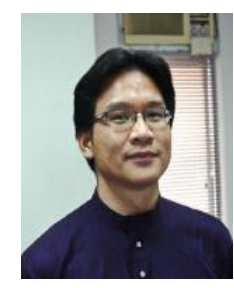

Wan Amir Fuad Wajdi Othman is currently a senior lecturer at School of Electrical and Electronic Engineering Universiti Sains Malaysia. He completed his bachelor of engineering at Toyohashi University of Technology, Japan. He completed his M.Sc. at University of Manchester Institute of Science and Technology,UK and his Ph.D at Sheffield Hallam University, UK. His specializations are in swarm robotics, artificial intelligence, and self organizing systems.

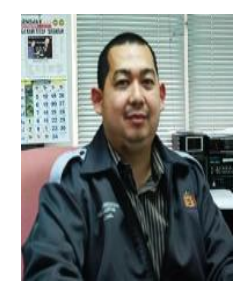

Aeizaal Azman Abdul Wahab is currently a senior lecturer at School of Electrical \& Electronic Engineering Universiti Sains Malaysia. He obtained his B.Sc and M.Sc. at Universiti Kebangsaan Malaysia. He completed his Ph.d at Universiti Sains Malaysia. His area of specializations are in discriminant analysis, time series and forecasting, multivariate techniques and data analysis.

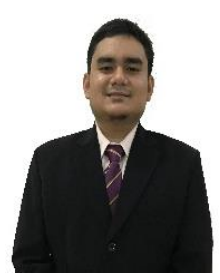

Mohamad Faiz Ahmad Johari is currently a research officer at School of Electrical and Electronic Engineering Universiti Sains Malaysia. He completed his Bachelor of Engineering (Electrical and Electronic) and Master of Science (Computational Intelligence) at Universiti Sains Malaysia. His current research interest is artificial intelligence, colour recognition and control systems. 